\title{
Incidence of Oral Cancer in a Tertiary Cancer Centre of Nepal: A Retrospective Study
}

\author{
Pravin Kumar Jaiswal ${ }^{1}$, Prabhat Thakur ${ }^{1}$, Kapil Thapa ${ }^{2 *}$
}

\section{Author Info:}

${ }^{1}$ Head \& Neck Oncology Unit, Nepal Cancer Hospital \& Research Center, Satdobato-Godawari Road, Lalitpur 44700, Nepal.

${ }^{2}$ Department of Zoology, Tri-chandra Multiple Campus, Tribhuvan University, Durbar-Marg, Kathmandu 44600, Nepal.

*Corresponding Author:

Mr. Kapil Thapa

Email/Contact:

thapakazzii000@gmail.com +9779862153467

\section{ABSTRACT}

Background: Oral cancer, which includes cancer of lips, gingiva, tongue, oropharynx, sinuses, and salivary glands, is fifth most common cancer in Nepal. The incidence of oral cancer may differ among gender, age, and site. This study aims to address the questions regarding the incidence and trend of oral cancer occurrence.

Methods: Oral cancer cases registered in the Head and Neck Oncology Department of Nepal Cancer Hospital \& Research Centre, Lalitpur, Nepal from 01 Jan 2018 to 31 Dec 2019 were included in this study. The data were categorized under gender, site of a tumor, year of diagnosis, and age of patients at diagnosis and entered in RStudio version-1.3.1093 for analysis.

Results: A total of 165 cases were found to be recorded where $74.5 \%$ were male and $24.5 \%$ were female. The most common site was the tongue (27.27\%) followed by the mandibular alveolus (19.39\%). The overall mean age was 53.71 years (95\% CI: 55.73-51.68). The number of new cases was found to be increased by $35.71 \%$ from 2018 to 2019 .

Conclusion: A significant increase in the number of new cases indicates that there are deficiencies in handling oral cancer in Nepal. Reducing the production, import, and consumption of tobacco and related products as well as ensuring accessible health facilities for all may help control this disease.

\section{Keywords:}

Tobacco; Cancer Care Facilities; Lip Neoplasms; Incidence; Nepal; Gingiva; Mouth Neoplasms

\begin{tabular}{|c|c|}
\hline QR Code & Article Info \\
\hline \multirow{4}{*}{$\begin{array}{l}\text { Scan Me for } \\
\text { Full Text }\end{array}$} & Published Online: 29 July 2021 \\
\hline & How to cite this article in Vancouver Style? \\
\hline & $\begin{array}{l}\text { Jaiswal PK, Thakur P, Thapa K. Incidence of Oral Cancer in a Tertiary Cancer Centre of Nepal: A Retrospective Study. } \\
\text { Europasian J Med Sci. 2021; 3(2):4-9 } \underline{\text { https://doi.org/10.46405/ejms.v3i2.256 }}\end{array}$ \\
\hline & Disclaimer \\
\hline \multirow[t]{2}{*}{$\triangle 1$ View PDF } & Conflict of Interest: None Declared; \\
\hline & Publisher's Note \\
\hline $\begin{array}{l}\text { Copyright (C) } 2021 \\
\text { licenses/by/4.0/) }\end{array}$ & $\begin{array}{l}\text { thor(s). This work is licensed under the terms and condition of Creative Commons Attribution International License } 4.0 @ \text { (1) (http: / / creativecommons.org/ } \\
\text { permits unrestricted use, distribution, and reproduction in any medium, provided the original work is properly cited. This is an open access publication, and can } \\
\text { rom the website of the Journal: www.europasianjournals.org. The Journal as well as publisher remain neutral with regards to any jurisdictional claims in any } \\
\text { ntents and the institutional affiliations of the authors. The Europasian Journal of Medical Sciences (EJMS) is an official Journal of Nirvana Psychosocial Care Center \& }\end{array}$ \\
\hline
\end{tabular}




\section{INTRODUCTION}

Oral cancer commonly refers to the carcinoma of stratified squamous epithelium. About $96 \%$ of cases of oral cancer are squamous cell carcinoma(SCC) and its subtypes and the rest of the cases are adenocarcinomas which is related to neoplastic change of glandular cells of the salivary gland. ${ }^{1}$ Oral cancer includes cancer of the lips, gingival, tongue, oropharynx, sinuses, and salivary glands. ${ }^{2}$

Several risk factors are directly or indirectly associated with cancer occurrence, the most common being tobacco of smokeless and smoking types, alcohol, betel-quid, phenolic reagents, radiation, iron deficiency, vitamin A deficiency, syphilis, oncogenic viruses such as human papillomavirus (HPV), genetic predisposition, etc. ${ }^{3}$ Again, tobacco is the most common and dominant risk factor. The relative risk for the heaviest versus the lowest smokers category ( $>100$ vs. $<1$ pack-years) is 14.8 and the risk levels decrease to the level of non-smokers after 10 years had elapsed since stopping smoking. ${ }^{4}$

Oral and pharyngeal cancer grouped is the sixth most common cancer in the world with an annual estimated incidence of around $275000 .^{5}$ The agestandardized incidence rate of lip/oral cavity in the whole world is 5.8 per 100000 and 2.3 per 100000 per female. ${ }^{6}$

The incidence of oral cancer has been distributed variously among gender, age, and site. In most countries, cases are seen more in men as they use smoke and tobacco for indulgence at higher rates. The ratio of males to females is about $1.5: 1$ for the mouth and about 2.8:1 for cancer of the oropharynx globally. ${ }^{5}$ The same study also showed that buccal cancer is the most common among the Asian population due to betel-quid/tobacco chewing habits, while a tongue is the most common site among European and United States (US) populations because betel-quid/ tobacco chewing habit is not observed in western countries.

The area characterized by high incidence rates for oral cancer, excluding lip, are found in South and Southeast Asia (Srilanka, India, Pakistan, and Taiwan), parts of Western (France) and Eastern Europe (Hungary), parts of Latin America and the Caribbean region ( Brazil, Uruguay, and Puerto Rico), and in Pacific regions (Papua New Guinea). ${ }^{5}$

The trend of cancer incidence is increasing alarmingly in most countries. Age-standardized incidence of oral cancer in Western Europe has steadily increased in the past two decades. In the United Kingdom (UK) since 1989 , an average increase of $2.7 \%$ each year has been reported. ${ }^{5}$ Over fifteen years (1986-2000) in a cancer registry in Mumbai, India, the incidence rate has decreased in men without any changes in women. ${ }^{7}$

Nepal too is not free from the grasp of oral cancer and the grasp is being even stronger day by day. In Nepal, lip and oral cancer rank fifth in position. ${ }^{8} \mathrm{~A}$ study in Eastern Nepal showed the ratio of male to female patients to be $2: 1 .^{9}$ Most patients were in the range of 45-54 years or more than 64 years and buccal mucosa was found to be the most affected site. Although studies have been done in-depth accounting for the status of overall cancer (eg. Nepal Health Research Council [NHRC], 2018) very few studies have been done focusing more on oral cancer. Amidst such a situation, this hospital-based study has put an effort to provide answers to the questions regarding its incidence and trend of occurrence within the country.

\section{MATERIALS AND METHODS}

All the oral cancer cases recorded from 01 Jan 2018 to 31 Dec 2019 in a tertiary cancer hospital-Nepal Cancer Hospital \& Research Centre, Lalitpur- were retrieved for the study after getting approval from the Institutional Review Committee (IRC). Only those cases which are mentioned under neoplasm of lip, oral cavity, and pharynx (C00-C14) by tenth revision of International Statistical Classification of Diseases (ICD), ${ }^{10}$ were included in the study. The cases of Basal Cell carcinoma were not included.

All the cases were categorized based on site, age, gender, and year of diagnosis. The subsites of the oral cavity were coded and categorized based on ICD-10. All the cases whether clinically diagnosed or histopathologically verified were included. The data was formatted year-wise and gender-wise. For the yearto-year analysis, cases of 2018 and 2019 were split accordingly into two different groups based on the year a subject is diagnosed.

Poisson regression was carried out to know how the number of cases is changing among gender, site, age, and year. To compare the case frequency between different age groups, the age of patients was categorized as young (20 years or below 20 years), adult (ranging from 20-50 years), and old (above 50 years). Similarly, to prevent excessive independent variables for the site of cancer, sites like buccal mucosa, alveolus, and retromolar trigone (RMT) were grouped as gingivo-buccal complex (GBC), and sites like a lip, oropharynx, tonsil, and overlapped sites, which had minor frequency, were grouped as 'Other' category. All the statistical analysis was 
done in the RStudio Desktop version 1.3.1093 which is a free and open access source tools for $\mathrm{R}$, a programming language, and can be downloaded from Comprehensive R Archive Network (CRAN). ${ }^{11}$

\section{RESULTS}

A total of 165 cases of oral cancer (C00-C14) were found to be registered in the Head and Neck department. Of total 165 cases, 123 (74.5\%) were male and 42 (25.5\%) were female. In the year 2018, 70 cases were recorded while in 2019 alone, 95 cases were reported. In the year 2018, the case count for males was 49 , and that for females was 21 , while in 2019, it was 74 and 21 for males and females respectively. It shows that number of male patients is increasing annually while that of females remaining constant.

Table 1 shows the number of patients suffering from cancer at different sub-sites of the oral cavity in different year according to their gender. The most common site was the tongue $(27.27 \%)$ followed by mandibular alveolus (19.39\%) and buccal mucosa $(13.33 \%)$. In males, the most common site was tongue (25.2\%) followed by mandibular alveolus (20.32\%) and buccal mucosa (14.63\%) while in females it was tongue $(33.33 \%)$ followed by mandibular alveolus (16.67\%) and maxillary alveolus (14.28\%). In 2018 , mandibular alveolus $(21.43 \%)$ was the most common site followed by a tongue $(20 \%)$ while in

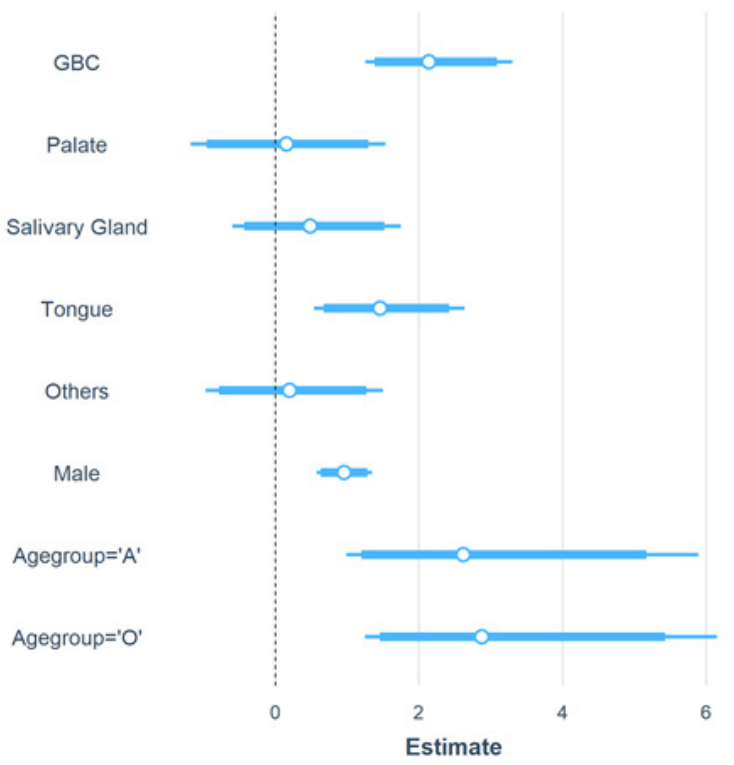

Figure 1: Logarithmic estimated values for each regression coefficient with a 95\% confidence interval. Variables Floor of mouth $(n=5)$, Female $(n=$ 42) and Age-group $Y(n=1)$ are acting as baseline.
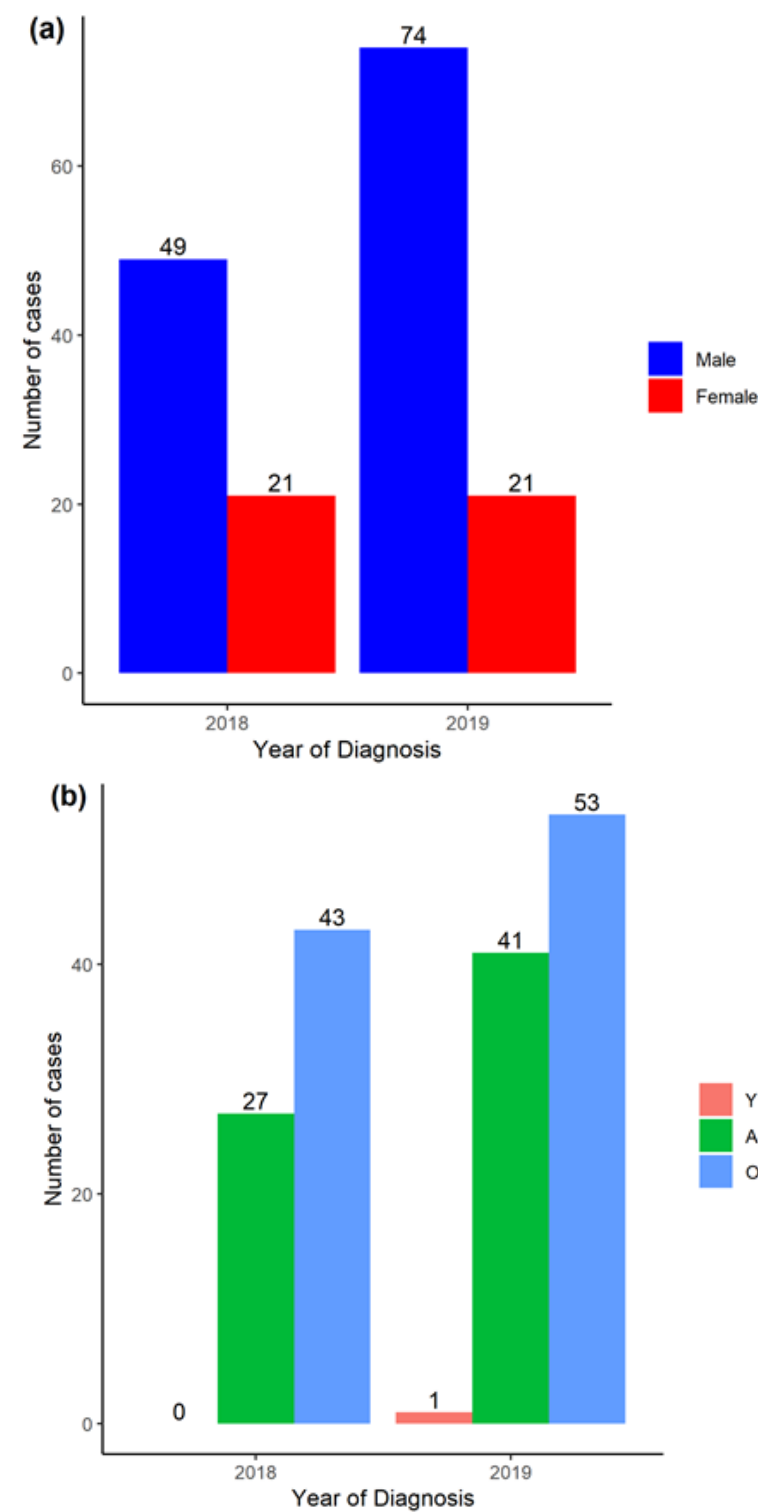

Figure 2: (a) Age-wise distribution of oral cancer cases in two different years. ' $Y$ ' refers young ( $<20 \mathrm{yrs}$ ), 'A' refers adult (20-50 yrs), and ' $O$ ' refers to old ( $>50$ yrs) (b) Genderwise distribution of cases in two consecutive years.

2019 tongue was the most common site (32.63\%) followed by mandibular alveolus (17.89\%).

For Poisson Modelling, all the variables such as site of neoplasia, gender of patients, year of diagnosis, and age-group that a patient belongs to, were included initially. But ANOVA analysis showed the "year of diagnosis" variable as insignificant thus it was removed from the model later. The final model showed that the case count in males was 2.59 times 
Table 1: Distribution of oral cancer cases at different sub-sites of the oral cavity in different years and gender.

\begin{tabular}{lllllll}
\hline \multirow{2}{*}{$\begin{array}{l}\text { Different sub-sites of the oral } \\
\text { cavity }\end{array}$} & \multicolumn{3}{l}{ Male Patients } & \multicolumn{2}{l}{ Female Patients } & \\
\cline { 2 - 5 } & $\begin{array}{l}\text { Diagnosed } \\
\text { in 2018 }\end{array}$ & $\begin{array}{l}\text { Diagnosed } \\
\text { in 2019 }\end{array}$ & $\begin{array}{l}\text { Diagnosed } \\
\text { in 2018 }\end{array}$ & $\begin{array}{l}\text { Diagnosed } \\
\text { in 2019 }\end{array}$ & Total in 2018 & Total in 2019 \\
\hline Upper lip (C00.0) & 0 & 1 & 0 & 0 & $0(0.00 \%)$ & $1(1.05 \%)$ \\
Tongue (C01+C02) & 6 & 25 & 8 & 6 & $14(20.00 \%)$ & $31(32.63 \%)$ \\
Mandibular alveolus (C03.0) & 13 & 12 & 2 & 5 & $15(21.43 \%)$ & $17(17.89 \%)$ \\
Maxillary alveolus (C03.1) & 6 & 9 & 4 & 2 & $10(14.29 \%)$ & $11(11.58 \%)$ \\
Floor of mouth (C04) & 2 & 2 & 1 & 0 & $3(4.29 \%)$ & $2(2.11 \%)$ \\
Hard palate (C05.0) & 0 & 0 & 0 & 1 & $0(0.00 \%)$ & $1(1.05 \%)$ \\
Soft palate (C05.1) & 0 & 2 & 0 & 2 & $0(0.00 \%)$ & $4(4.21 \%)$ \\
Buccal mucosa (C06.0) & 9 & 9 & 3 & 1 & $12(17.14 \%)$ & $10(0.53 \%)$ \\
Retromolar Area (C06.2) & 5 & 6 & 2 & 0 & $7(10.00 \%)$ & $6(6.32 \%)$ \\
Overlapping site (C06.8) & 1 & 0 & 0 & 1 & $1(1.43 \%)$ & $1(1.05 \%)$ \\
Unspecified (C06.9) & 0 & 0 & 1 & 0 & $1(1.43 \%)$ & $0(0.00 \%)$ \\
Parotid gland (C07) & 5 & 5 & 0 & 1 & $5(7.14 \%)$ & $6(6.32 \%)$ \\
SMG (C08.0) & 0 & 1 & 0 & 1 & $0(0.00 \%)$ & $2(2.11 \%)$ \\
Tonsil (C09) & 0 & 1 & 0 & 0 & $0(0.00 \%)$ & $1(1.05 \%)$ \\
Oropharynx (C10) & 2 & 1 & 0 & 1 & $2(2.89 \%)$ & $2(2.11 \%)$ \\
Total & 49 & 74 & 21 & 21 & $70(100 \%)$ & $95(100 \%)$ \\
\hline
\end{tabular}

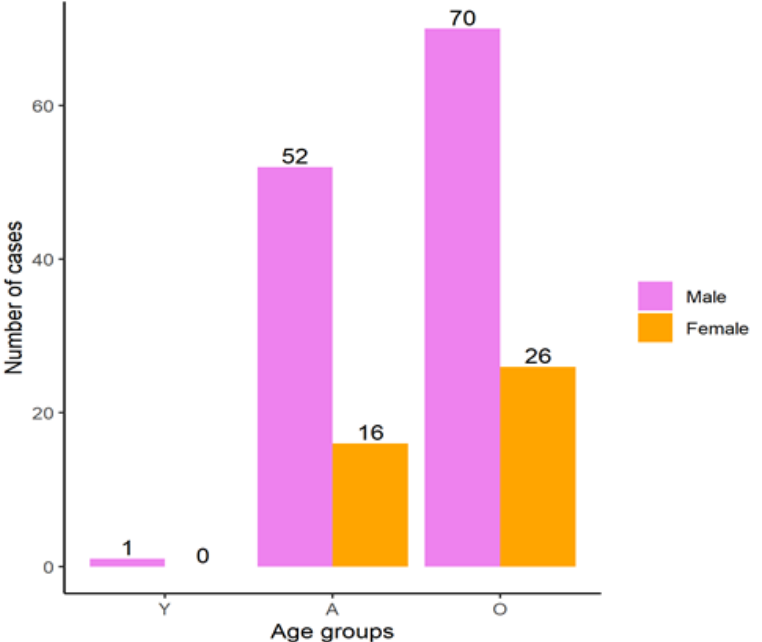

Figure 3: Age-wise distribution of cases in different gender

the count in females ( $\mathrm{p}=.00006)$. Similarly, the case count in the adult and old age groups was much higher than for the young. In the adult, the case count was 13.69 times that for young $(\mathrm{p}=0.03)$, and for old it was 17.68 times $(\mathrm{p}=0.01)$. Considering "floor of mouth" as a baseline ( $\mathrm{n}=5)$ in the regression model, the count was highest (8.44 times) for GBC $(\mathrm{p}=0.0003)$ followed by a tongue (4.27 times) $(\mathrm{p}=0.01)$. All the estimates of respective regression coefficients are shown in Figure 1.

The mean age of males at diagnosis was 53.41 years (95\% CI: 55.70-51.12) and in a female, it was 54.57 years (95\% CI: 58.89-50.25). The overall mean age was 53.71 years ( $95 \% \mathrm{CI}: 55.73-51.68)$. In year basis, the mean age was 53.05 years ( $95 \% \mathrm{CI}$ : $55.76-50.34$ ) in 2019 and 54.6 years (95\% CI: $57.65-51.55$ ) in 2018. This shows; in male and the year 2019; more young people have been affected. However, there wasn't a significant difference in mean age between gender $(p=0.64)$ and also between years $(p=0.46)$. Only one case of under age 20 years was found in 2019. The patient was a male with carcinoma of the alveolar ridge.

In total, there was an observed increment in the number of cases by $35.71 \%$. Figures $2 \mathrm{a}$ and $2 \mathrm{~b}$ depict the gender-wise and age-wise distribution of cases in two different years respectively. There was an enormous annual increase (by 51.02\%) in males while the number of cases in females from 2018 to 2019 was found to be constant. In age groups, the frequency of cases was found to increase at a higher rate among adults by $51.85 \%$ as compared to $23.25 \%$ in the older groups.

In total, $0.61 \%$ case was in young age-group, $41.21 \%$ in adults, and $58.18 \%$ in older age groups. During both years, the number of the older patient was higher. No case of the young population was found in 2018. Similarly, in both genders, the number of old patients was higher. No case of young female was found (Figure 3).

\section{DISCUSSION}

Based on analytical viewpoints such as prevalence 
based on gender, anatomical sites, and in different age groups, there is more or less the same inference in the national, international, and globally recognized works done on oral cancer trends in the past. This work also supports the same trend.

To a global extent, Warnakulasuria had shown the ratio of male to female was about 1.5:1 for mouth cancer. $^{5}$ Zhang et al in another study showed the ratio to be 1.97:1while Sugarman et al showed it to be 2.2:1.12,13 This study found that males are more vulnerable to oral cancer, showing the male to female ratio to be 2.95:1. Most studies demonstrate males are more commonly affected as compared to females which can be attributed to more indulgence with tobacco among men. ${ }^{14}$

Similarly, a study in Allahbad, India had shown tongue as the most common site (37.8\%) followed by buccal mucosa $(33.7 \%)$ while Byakodi et al showed alveolus as the most common site $(32.14 \%)$ followed by buccal mucosa (30.35\%). ${ }^{15,16}$ A hospital-based study in Nepal showed tongue as the most common site. ${ }^{17}$ As the study of Poudel et al this study showed tongue as the most commonly affected site (27.11\%) followed by gingivobuccal sulcus (GBS) (15.66\%).

Tandon et al reported that the most commonly affected (39.5\%) age group was above 50 years while the least affected $(0.19 \%)$ age group was below 20 years. ${ }^{14}$ In this study, the most commonly affected (58.43\%) age group was above 50 years and the least affected $(0.602 \%)$ age group was below 20 years. There are many reasons why older people are more commonly affected. The relative risk of cancer increases with age. ${ }^{18}$ This is because, the older the age, the higher is the tendency of gene mutation. Another reason is the time from exposure to event analysis. Even if a person has been exposed to the risk factors at an earlier age, it takes significant time to start the genetic change by carcinogens. There is 25-years latency between the initial exposure to a carcinogen and the development of cancer. ${ }^{19}$

A study in Karachi, Pakistan showed that the females suffering from oral cancer had a mean age of 50.0 years (95\% CI 48.2- 52.4) at diagnosis while in the male it was 51.2 years (95\% CI 49.4- 53.1). ${ }^{20}$ In our study, the mean age of males at diagnosis was 53.48 years (95\% CI: 55.76-51.21) and in females, it was 54.57 years (95\% CI: 58.89-50.25), whereas, in Khon Kaen, Thailand the mean age of whole patients at diagnosis was 63 years. ${ }^{21}$ Our study showed the mean age was 53.76 years (95\% CI: 55.77-51.74) which indicates Nepalese are being affected at a younger age.
Howell et al reported an $84 \%$ increase in the number of oral cancer cases in females and a $23 \%$ increase in males over 5 years in Nova Scotia. ${ }^{22}$ On the contrary, our study found a significant annual increase, by $48 \%$, in males while the number of a female with oral cancer remained constant. In age groups, the frequency of cases is increasing at a higher rate among adults by $51.85 \%$ as compared to $20.45 \%$ in olds. This infers that the more exposure of adults to the risk factor, most likely being tobacco.

A nationally representative study by Shrestha et al have found that the overall prevalence rate for any form of tobacco use was higher in males (52.3\%) than in females $(8.4 \%) .^{23}$ Apart from changing lifestyles and food habits of people, the lack of proper health facilities across the country can be directly attributed to the increasing incidence of oral cancer. The World Health Organization (WHO) recommends a 1:7,500 dentist to population ratio but in Nepal, it is as low as 1:47306. ${ }^{24,25}$ This prevents rural people from getting proper health education, recommendations, and treatment facilities. While it is true that the probability of preventing oral cancer is high if it is detected earlier, the sparse or no visit to the hospital for a longer period enhances the risk of disease advancing to higher stages. ${ }^{22}$ The higher cost of diagnostic and curative approaches for cancer has further increased complications dealing with its control because of the inability of the majority of people to afford the cost of health checkups and treatment.

This hospital-based study although would be a strong reference for other study studies in the future, may not represent the actual trend of oral cancer incidence across the whole country. Moreover, if more than two years were included for studying the trend, would have further standardized the study.

\section{CONCLUSION}

The significant annual increase in oral cancer count has reflected a dire scenario of oral health of Nepali people. Males aged over 50 years are found most vulnerable to oral cancer and more indulgence of men to tobacco might be a contributing factor for this. Thus, the authorities should be focused on the strict implementation of plans and policies for controlling, investigating, and prohibiting the sale of tobacco and related products. People aged over 50 years should also be encouraged for regular oral health checkups. Moreover, an easily available and accessible health facility for all economic classes of people is a must.

Acknowledgment: We are highly grateful to Prof. Dr. Mohan Niraula and Asst. Prof. Puja Jaiswal, 
Department of Zoology, Tri-chandra Multiple Campus, Tribhuvan University, for helping to design the research and also Dr. Anju Shrestha and Dr. Murari Man Shrestha, Nepal Cancer Hospital \& Research Center, for their invaluable support in many instances till the completion of this research.

\section{REFERENCES}

1. Siddiqui S, Chandra, R, Aziz, A and Suman, S. Epidemiology and Histopathological Spectrum of Head and Neck Cancers in Bihar; A State of Eastern India. Asian Pacific Journal of Cancer Prevention. 2012; 13: 3949-3953. https://doi.org/10.7314/ APJCP.2012.13.8.3949. [Google Scholar] [PubMed]

2. WebMD. 2017; Oral Cancer. https://www.webmd.com/oralhealth/guide/oral-cancer\#1. Acessed on $20^{\text {th }}$ July 2019 . [Link]

3. Chovatiya NR, Modi TG, Choksi VA, Shah S, Majeethia D. Oral Squamous Cell Carcinoma Variants- A clinic- pathologic relevance. IOSR Journal of dental and Medical Sciences. 2018 17(5): 25-30. 10.9790/0853-1705142530 [Google Scholar]

4. Franco EL, Kowalski, LP, Oliveira, BV, Curado, MP, Pereira, RN Silva, ME et al. Risk factors for oral cancer in Brazil: A casecontrol study. International journal of cancer. 1989; 43: 9921000. https://doi.org/10.1002/ijc.2910430607_[Google Scholar] [PubMed]

5. Warnakulasuriya S. Global Epidemiology of Oral and Oropharyngeal Cancer. Oral Oncology. 2009; 45: 309-318. https://doi.org/10.1016/j.oraloncology.2008.06.002 [Google Scholar] [ubMed]

6. GLOBOCON, 2018. Cancer fact sheets. Retrieved from https://gco.iarc.fr/todav/fact-sheets-cancers. Accessed on 17 march 2020. [Link]

7. Sunny L, Yeole BB, Hakama M, Shiri R, Sastry PSRK, Mathews S. et al. Oral Cancers in Mumbai, India: A Fifteen Years Perspective with Respect to Incidence, Trend and Cumulative Risk. Asian Pacific Journal of Cancer Prevention. 2004; 5: 294-300. [Google Scholar] [PubMed]

8. Nepal Health Research Council. Population based Cancer Registry in Nepal: Interim analysis of data. NHRC. Ramshahpath, Kathmandu, Nepal. 2018. [Link]

9. Rimal J, Shrestha A, Maharjan IK, Shrestha, S, Shah P. Risk Assessment of Smokeless Tobacco among Oral Precancer and Cancer Patients in Eastern Development Region of Nepal. Asian Pacific Journal of Cancer Prevention. 2019; 20(2): 411-415. https://doi.org/10.31557/APICP.2019.20.2.411 [Google Scholar] [PubMed]

10. WHO. International Statistical Classification of Diseases and Related Health Problems (ICD), $10^{\text {th }}$ edition, World Health organization, Geneva. 2018. [Link]

11. The Comprehensive R Archive Network.Accesssed [2021 February 6] Available from: https://cran.r-project.org/. [Link]

12. Zhang SK, Zheng R, Chen Q Zhan S, Sun X, Chen M. Oral Cancer Incidence and Mortality in China. Chin J Cancer Res. 2011; 27(1): 44-51. 10.3978/i.issn.1000-9604.2015.01.03[Google Scholar] [PubMed]

13. Sugerman PB, Savage NW. Oral cancer in Australia: 19831996. Australian Dental Journal. 2002; 47(1): 45-56. https:// doi.org/10.1111/i.1834-7819.2002.tb00303.x [Google
Scholar] [PubMed]

14. Tandon P, Diadhich A, Saluja H, Bawane S, Sachdeva S. The Prevalence of Squamous cell Carcinoma in different sites of Oral cavity at our rural Health care centre in loni, Maharastra- a retrospective 10- yearstudy. Contemporary Oncology. 2017; 21(2): 178-183. 10.5114/wo.2017.68628 https://doi.org/10.5114/wo.2017.68628 [Google Scholar] [PubMed]

15. Mehrotra R, Pandya S, Chaudhary AK, Kumar M, Singh M. Prevalence of oral Pre- malignant and Malignant lesions at a tertiary level Hospital in Allahabad, India. Asian pacific journal of cancer prevention. 2008; 9: 263-266. [Google Scholar] [PubMed]

16. Byakodi R, Byakodi S, Hiremath S, Byakodi J, Adaki S, Marathe $\mathrm{K}$, et al. Oral cancer in India: An Epidemiologic and Clinical Review. J Community Health. 2011; 37:316-319. https:// doi.org/10.1007/s10900-011-9447-6 [Google Scholar] [PubMed]

17. Poudel KK, Huang Z, Neupane PR, Steel R, Poudel JK. Hospitalbased cancer Incidence in Nepal from 2010 to 2013. Nepal Journal of Epidemiology. 2017; 7(1): 659-665. 10.3126/ nje.v7i1.17759 https://doi.org/10.3126/nje.v7i1.17759 [Google Scholar] [PubMed]

18. Luis A, Adriana P, Daniel R. Trend in frequency and prevalence of oral cancer and oral squamous cell carcinoma in Mexicans: A 20 years retrospective study. Oral Medicine and Pathology. 2011; 16(1); 21-25. https://doi.org/10.4317/medoral.16.e1 [Google Scholar] [PubMed]

19. Phillips PA. The basic science of oncology.1987; Newyork, Pergamon Press, 25 pp [Link]

20. Bhurgri Y. Cancer of Oral cavity- Trends in Karachi South (1995-2002). Asian Pacific J Cancer Prev. 2005; 6: 22-26. [Google Scholar]

21. Vatanasapt P, Suwanrungruang K, Kamsaand S, Promthet $\mathrm{S}$, Parkin MD. Epidemiology of oral and pharyngeal cancers in Kon Kaen, Thailand: A high incidence in females. Asian Pacific Journal of Cancer. 2011; 12:2505-2508. [Google Scholar] [PubMed]

22. Howell RE, Wright BA, Dewar R. Trends in the Incidence of oral cancer in Nova Scotia from 1983 to 1997. Oral Surgery Oral Medicine Oral Pathology. 2003; 95: 205-212. https:// doi.org/10.1067/moe.2003.49 [Google Scholar] [PubMed]

23. Shrestha N, Mehata S, Pradhan PMS, Joshi D, Mishra SR. A nationally representative study on socio-demographic and geographic correlates, and trends in tobacco use in Nepal. Sci Rep. 2019; 9: 2682. https://doi.org/10.1038/s41598-01939635-y [Google Scholar] [PubMed]

24. WHO Expert Committee on Recent Advances in Oral Health \& World Health Organization. [1992|" Recent advances in oral health: report of a WHO expert committee [meeting held in Geneva from 3 to 9 December 1991]]. World Health Organization. https://apps.who.int/iris/ handle/10665/39644 [Link]

25. WHO Oral Health Country/Area Profile Programma (CAPP) Oral Health Manpower. http://www.mah.se/CAPP/ Country-Oral-Health-Profiles/SEARO/Nepal/Oral-HealthManpower/. Accessed on $6^{\text {th }}$ of Nevember 2020. [Link] 